\title{
NON-LINEAR GEOGRAPHICS AND THE ECONOMICS OF TRANSITION AND DEMOCRATIZATION
}

\author{
Elise S. Brezis* and Thierry Verdier**
}

\begin{abstract}
The purpose of this paper is to analyze the effects of geography on the transition process in authoritarian political regimes, and to investigate the nature of the links between political change, economic reforms and geographic location. A simple model of transition and democratization is presented wherein we show that the effectiveness of repression by the incumbent elite is a negative function of the distance to the "free world". In consequence, there are conflicting effects of geography on political power shifting. The paper provides a rationale for the counterintuitive fact that the first authoritarian country to start a transition process towards democratization is not necessarily the one nearest to the free world.
\end{abstract}

Keywords: conflicts; democratization; elites; geography; repression; transition process. IEL classification: D74; P26; P36.

* We wish to thank the Editor, the referees as well as Jean-Pascal Bénassy, Francois Bourguignon, Cecilia Garcia-Penalosa, Adam Przeworski and seminar participants at Strasbourg, Tel-Aviv University, and the PSE for their helpful comments on earlier versions of this paper.

* Bar-Ilan University, and Paris School of Economics. Email: elise.brezis@biu.ac.il

** Paris School of Economics and CEPR. Email: verdier@pse.ens.fr 


\section{Introduction.}

In recent years, the economic literature on democratization, transition, and regime changes has focused mainly on the political economic dimensions, stressing in particular the importance of redistributive conflicts between various groups in society. ${ }^{1}$ This literature has highlighted the importance of specific socio-economic determinants of democratization such as income inequality, factor endowments or production technologies.

One element relatively neglected by this literature is the role of geography and space, and their influences on the evolution of political regimes. This negligence is quite at variance with studies in other social sciences, since anthropologists, economic historians and political scientists have for long recognized that geographic and spatial specificities may play an important role in the evolution and emergence of political systems. ${ }^{2}$

The purpose of this paper is to analyze the effects of geography on the transition process in authoritarian political regimes, and to investigate the nature of the links between political change, economic reforms and geographic location. The view that geographic variables have significant impact on the nature of political relations is linked to a well established literature in international relations, which argues that climate, topography, and location are important determinants of state behavior. ${ }^{3}$ Similarly, historians such as Blockmans $(1978,1997)$ highlight the significant influence that geographic scale and compactness have on the type of representative institutions of pre-modern European polities. Bairoch (1997) as well stressed that the compactness of small states with strong regional autonomy in the political system leads to early economic development.

In a recent work, Stasavage (2009) investigates the importance of geographic factors in shaping the degree of representativeness of political institutions. He argues that geographically compact polities can more easily sustain intensive forms of political representation. His analysis suggests a strong effect of geographic scale on the formation of political representation.

\footnotetext{
${ }^{1}$ The various possible redistributive conflicts we face are usually among capitalists vs. landowners or workers; incumbents versus new entrants; and elites vs. demos. See for instance Acemoglu and Robinson (2005), Acemoglu (2006), Bourguignon and Verdier (2010), and Brezis and Temin (2008).

${ }^{2}$ For instance, Carneiro (1970, 1978) and Mann (1986) emphasized the importance of conditions of territorial "circumscription" in the formation of primary states based on irrigation in river valleys. They showed that new transportation technologies stimulated changes in political organizations and the spatial limits of power.

${ }^{3}$ See Boulding (1962), Sprout and Sprout (1965), and Diehl (1991).
} 
More recently, the transition process in Eastern Europe is an interesting example of the impact of geography and space on the evolution of political systems. Indeed, the political liberalization and democratization process seemed to be related to contradictory geographic channels.

As a matter of fact, one might reasonably expect that a shorter distance to the West would facilitate support for dissidence against the old regime and therefore make a shift of regime more likely. However, transition to democracy actually began in countries located further from the "free world" frontier. Indeed, although the nearest country to the West was East Germany, it was Poland and Hungary that first underwent a change of regime, with the process then spreading eastward and westward. Why is it so, and why do we observe such spatial "non-linearity" in changes of political regimes?

The purpose of this paper is to provide a possible explanation for this observation, by explicitly introducing space and distance into a simple model of democratization and political regime change. To do so, we highlight how geography interacts with the military aspects of conflict and repression. In this paper, we show that geographic distance which affects the costs of escaping from a country will endogenously affect the scale of repression. ${ }^{4}$

At the heart of the analysis lies the assertion that the repressive capacity of an incumbent political elite is affected by the spatial ability of dissidents to escape the regime. This ability in turn is determined by the distance to safe havens, or the "free world". The closer to that frontier, the easier it is for dissidents to escape the authoritarian regime run by the incumbent elite. All else being equal, this reduces the expected costs of dissidence, thereby stimulating stronger incentives for counter-regime activities, implying power shifting to be more likely in political regimes located closer to the "free world" frontier. This link therefore provides a first direct channel through which geography and space circumscribe the nature of political power and tend to favor democratization.

There is however, as well, an induced channel through which geography interacts with conflicts and politics. Indeed, the size of the repressive forces in a given authoritarian regime is not exogenous, but rather actually results from the choice made by the incumbent elite to maintain itself into power. This feature implies in particular that the size of the repressive apparatus will be a function of the geographical characteristics of the country. As a matter of fact, countries with easier

\footnotetext{
${ }^{4}$ The notion of geography is vast, going from questions of location, compactness or topology. In this paper, we refer to the elements which influence the costs of escaping. It is mostly distance, but also the topology of the region.
} 
access to "safe havens" will face stronger repressive efforts from their elites than countries where such access is more difficult.

The rationale underlying this relationship is simple. Geographic distance and policing are substitutes from the point of view of the expected cost of sanction as perceived by dissidents in a given country. The closer the country is to "safe havens", the more likely are the dissidents to decide to move and escape whenever an uprising is repressed. So the more profitable, in terms of perceived sanctions, it is for the regime to police after the underground dissidents trying to flee to the free world. It follows from this that there should be more intensive policing and repressive apparatus in countries closer to the "free world" frontier than in countries located further from such frontier. This second induced effect of geography enters with opposite sign compared to the first direct channel of distance.

These conflicting effects of geography on political power shifting lie at the source of these intricate patterns of democratization processes. They may therefore explain the sequence of political liberalizations and economic transitions observed across Eastern Europe in the late 1980s.

This paper is related to several recent lines of research on democratization in the economic literature. With its focus on the microeconomics of the geography of political repression, our paper is connected to that of Gates' work (2002) on the micro-foundations of rebellion showing how geography interacts with ethnicity and ideology to determine military success and shape rebels' recruitment activities. Similarly, this paper is related to the empirical development literature that considers the influence of geographic attributes on conflicts. ${ }^{5}$

Our paper also has some connections to recent economic theories of size of nations, for instance that of Alesina and Spolaore (2003), which highlights the main factors affecting political integration decisions. Distance matters because of the way it influences the tradeoff between efficiency of provision of public goods and the differentiated preferences of agents over such goods. ${ }^{6}$

In the present paper, we depart from this literature in two ways. First, we break the symmetry across political agents and focus on the spatial determinants of political power shifting between an incumbent elite and a repressed mass of citizens. Second, rather than through the provision of public goods, geographic

\footnotetext{
${ }^{5}$ See Fearon and Laitin (1999), Collier and Hoeffler (1998), or Herbst (2000).

${ }^{6}$ Indeed, these models emphasize that the optimal size of nations results from a basic tradeoff between economies of scale in public goods production and increasing political costs associated with heterogeneity of preferences across citizens with respect to these goods. See also Spolaore (2008) for a study on the specific case of civil wars and domestic secessions. On geography and economies of scale, see also Krugman, 1991 and Brezis and Krugman, 1997.
} 
distance matters here through the effectiveness of the repressive apparatus of the state at dissuading dissidents from undertaking a revolution. This departure lies at the source of the contradictory effects of geography on political regime change.

The paper is organized in the following way. In section 2, we present the basic model. Section 3 then discusses the political economy equilibrium. In section 4 , we analyze changes in political regimes, and we show how distance from the "free world" affects the costs of dissidence and upheaval. Section 5 concludes.

\section{The Model}

The structure of our framework is based on models of autocratic regimes as presented in Acemoglu (2006), and Bourguignon and Verdier (2000, 2010). There are two groups of agents in this economy: the elites in power; and the citizens which we denote also as the workers.

The elites make decisions on three different levels, which affect their political power and state capacity. First, they choose the level of repressive forces as well as the extent of redistribution of output in society. The elites also decide whether to stay in power or if necessary, to leave their autocratic regime, resign and move towards democracy. The citizens make only one decision which is either to fight and try to move towards democracy, or to accept the political system of autocracy.

In this framework, democracy can be reached in two different ways. Either as a result of an upheaval, in which the elite looses power, or without a fight, when the elite comes to the decision that resigning and letting democracy flourish can be optimal. The latter situation will only occur if under the democracy regime, the elite is able to embezzle enough resources and wealth, through privatization, taxes or asset predation. ${ }^{7}$

In this framework, there are three possible equilibria. (i) The situation in which elites resign and lead to democracy (ii) the situation in which the elites stay in power but citizens decide to change the regime and fight. (iii) Finally the third regime is when elites stay in power and citizens decide not to fight. Before analyzing the different payoffs and outcomes under these three regimes, we define the basic structure of the model.

\footnotetext{
7 The literature on the relationship between privatization and political reforms in Eastern Europe is vast. See in particular Bolton and Roland (1992), Blanchard et al. (1994), Boycko et al. (1995), Lipton and Sachs (1990), Roland (2000), Brezis and Schnytzer (2003), and Brezis and Verdier (2003).
} 


\section{A. Political Power}

The elite group in a non-democratic state tries to retain its power and use it to maximize its resources and wealth. It determines the distribution of resources between workers, and themselves. Moreover it maintains a repressive force in order to prevent citizens from attempting to overthrow the regime.

Citizens can fight to take power, leading to democracy. They act in this way, when it is profitable to do so. In other words, they fight if their expected income is higher when they fight than when they do not fight.

\section{B. Timing of decisions}

There are two stages in this model. In the first stage, the elite makes its own decisions, and in the second stage the people decide whether to start a conflict or not. $^{8}$

The decisions made by the elite are: The elite decides how to allocate resources to the citizens, it chooses the level of repressive forces, and it also decides whether to stay in power, or to resign.

The reason why the elite group could decide to resign and let democracy happen is because democracy could allow them to keep peacefully, enough resources for themselves through embezzlement, corruption, political influences or legal system manipulations. We denote by $U_{R}^{*}$ the level of utility that the elite group can ensure through such strategy under democracy.

\section{Conflicts and Costs of Conflicts}

Citizens decide to overthrow the regime if, in expectation, it is in their interests to do so. ${ }^{9}$ If they fight, then with probability $p$, they overthrow the regime. This probability, $p$ defined on the closed interval $[0,1]$, is a decreasing function of the means of repression, $\beta$, such that:

$$
p=p(\beta) \text { and } p^{\prime}<0
$$

\footnotetext{
${ }^{8}$ The present model is static. We could have presented a dynamic recursive game between the elite and the citizens in which each party would make decisions, taking into account the dynamics of upheavals and democratization. The simpler structure presented in this paper allows us to focus clearly on the elements which play a key role in the relationship between geography and democratization, at the costs of simplifying some other elements of the model.

9 For sake of simplicity, we do not tackle the "collective action problem" and the free-riding of individuals among the citizens. We assume that the citizens behave as a group, or equivalently, we assume that the leaders of the revolution are the ones to be punished in case of unsuccessful revolution, and the one to get output in case of a successful one.
} 
For the sake of simplicity, we assume that the probability function is linear and takes the form: $p(\beta)=1-\delta \beta$, and $\beta$ being between zero and $1 / \delta$.

Should the revolution be successful, workers seize all output $Y$, while the elite loses their resources. Conversely, a failed revolution leads to a set of punitive actions against the citizens. These sanctions, taken for having tried to overthrow the regime, affect the utility level of citizens. Denote the level of utility in case of failed revolution as: $-E<0$. $E$ is the "punitive level" of utility.

Many variables affect the size of this punitive level in case of a failed revolution, $E$. Indeed, after a non-successful uprising, there are two possibilities facing the dissidents. (i)They can either stay in their country, risk arrest, and face a penalty of value $A$.

(ii) As an alternative, dissidents in danger of being caught can escape to the "free world", which is at distance $x$ from the political center of their country. In this alternative though, dissidents face "escaping costs", $Z$.

One part of the escaping costs is the cost related to the easiness of escaping repression. This cost depends on the level of the repressive forces of its country, $\beta$ and the higher the repressive forces, the higher the costs of escaping.

The second part of the escaping costs is the transportation cost, which is a positive function of the distance of the political center to the free world, $x$ and to the transportation costs per unit of distance, $t$, and takes the form: $t \varphi(x)+\lambda$ where $\varphi^{\prime}(x)>0$, and $\lambda>0$ is a constant. For the sake of simplicity, we assume that both elements enter the total costs of escaping, $Z$ in the following form: ${ }^{10}$

$$
Z(t)=[t \varphi(x)+\lambda] \beta
$$

Transportation costs per unit of distance, $t$ is a stochastic variable, since there are periods of the year and regions in the country where the costs are higher. Moreover, the state of the roads or transportation communications can be different at different times in the year due to the weather. For simplicity, we assume that $t$ is distributed uniformly on $\left[0, t_{h}\right]$ with $t_{h}$ being the maximum transportation costs, which may be affected by exogenous foreign political factors, as the international political arena. We denote the average costs of transportation as $\bar{t}$, which is equal to:

$$
\bar{t}=t_{h} / 2
$$

We assume that at the time of making their decision to engage in a popular upheaval, citizens do not know the exact realization of $t$ that will prevail when the

${ }^{10}$ This specific function will allow us to obtain an explicit functional form for the optimal amount of repressive forces, but is not necessary to get the main results presented in this paper. 
upheaval fails. Therefore ex-ante when deciding whether to fight or not, they only know the expected costs of transportation. The decision for a dissident to escape after an unsuccessful upheaval is then simply given by the comparison between $Z$, the cost of escaping, and $A$, the cost of the sanction in his country if he does not escape. ${ }^{11}$

Hence, when the realization of $t$ is low enough, dissidents escape to the "free world", while when it is high enough, they decide to stay, knowing that they will be caught. The punitive level in each case takes the form:

$$
\begin{aligned}
& \text { if } t \leq(A-\lambda \beta) / \beta \varphi(x) \text { then } E=Z \\
& \text { if } t \geq(A-\lambda \beta) / \beta \varphi(x) \text { then } E=A
\end{aligned}
$$

Hence ex-ante, when $\mathrm{A}$ is not too big such that $\beta\left[t_{h} \varphi(x)+\lambda\right]>A$, the expected punitive level for a citizen, $E$ will be given by:

$$
E(\beta, x)=\int_{0}^{(A-\lambda \beta) / \beta \varphi(x)} \frac{Z(t)}{t_{h}} d t+\int_{(A-\lambda \beta) / \beta \varphi(x)}^{t_{h}} \frac{A}{t_{h}} d t
$$

So that:

$$
E(\beta, x)=A-\frac{(A-\lambda \beta)^{2}}{4 \beta \bar{t} \varphi(x)}
$$

As it is clear from equation (3), the punitive level, $E$ is a positive function of three elements: the distance of the country to the "free world", $x$; the level of repressive forces, $\beta$; and the average transportation costs, $t$.

We make the following assumption regarding the level of the sanction costs:

Condition $I: \quad \lambda / \delta<A<\left(t_{h} \varphi(x)+\lambda\right) / \delta$

This condition ensures that the expected punitive level, $E$ is always positive for all admissible $\beta$, and that it is an increasing function of $\beta$. Moreover the right-hand side condition ensures that the solution of the elite maximization problem is in the

\footnotetext{
11 Costs of escaping are a function of the level of the repression, since the lower the size of the police and army, the easier it is to escape, but once they are caught, we assume that the punishment is of a given exogenous size of A which goes from harassment to years of prison or even death toll.
} 
region $\beta\left[t_{h} \varphi(x)+\lambda\right]>A$, in which the two possibilities occur: for low realization of $t$, dissidents escape, and for high $t$, they get caught. ${ }^{12}$

\section{Payoffs of the last stage of the game:}

There are three possible sets of payoffs. The first set follows the elite's decision to give up political power, resign and accept the move from an autocratic regime to a democratic one. We define the payoffs for workers and the elite in this case as respectively: $V_{R}$ and $U_{R}$ (R denoting 'resign').

The second arises when the elite chooses to remain in power but workers fight, the payoffs to workers and elite, respectively being $V_{F}$ and $U_{F}$ (F for 'fight'). The third set arises when the elite stays in power and workers do not fight, with payoffs $V_{N F}$ and $U_{N F}$ (no-fight).

\section{(i) Resigning}

As explained above, when the elites withdraw from power, they keep to themselves state assets, which generate a utility level of $U_{R}^{*}$. One of the most efficient way for embezzling assets is through privatization. The rulers essentially write out title deeds to state property to themselves. This way the elites are selling state properties to themselves at very low price, so that they obtain substantial pecuniary benefits from the transaction.

\section{(ii) Staying in power}

When the elite decides to stay in power, it determines the allocation of output $Y$ among themselves, $R$, and the citizens, $W$. We assume that the elite cannot give the citizens less than some bundle that is the minimum necessary for subsistence normalized to 0 .

So the citizen's payoffs are:

$$
V_{N F}=W \text { and } W \geq 0
$$

while the elite get the rents $\mathrm{R}$ and the payoff is:

$$
U_{N F}=R=Y-W
$$

\footnotetext{
${ }^{12}$ In case the right hand side of condition I does not hold, then $E=\beta[\bar{t} \varphi(x)+\lambda]$.
} 


\section{(iii) Conflicts}

The other alternative for the citizens, when the elite stays in power, is to fight. As stated before, should the revolution be successful, citizens seize all output, while the elite's payoff is zero. Conversely, a failed revolution leaves citizens with their wage $W$ but they are punished with an expected punitive level $-E<0$ for having tried to overthrow the regime. In such a case, the payoffs for them and the elite are: ${ }^{13}$

$$
\begin{aligned}
& V_{F}=p(\beta) Y+[1-p(\beta)][W-E] \\
& U_{F}=[1-p(\beta)] R=[1-p(\beta)][Y-W]
\end{aligned}
$$

In the next section, we determine the equilibrium of the system.

\section{Equilibrium}

An equilibrium is a set of decisions by the elite in the first stage, and by the citizens in the second stage. In the first stage, the elite chooses the size of the repressive forces, they choose whether to resign, and the allocation of output, and in the second stage, citizens decide whether to fight or not. The following lemma outlines the optimal decision of the elite.

\section{Lemma 1}

(i) When in the second stage, citizens fight, then in the first stage, the elite's best response is providing them the lowest allowable payoff; that is: $W=0$. In consequence, $U_{F}=[1-p(\beta)] Y$.

(ii) When in the second stage citizens do not fight, then in the first stage, it is optimal for the elites to allocate for citizens : $W=p(\beta) Y-[1-p(\beta)] E$ and the elite's payoff is: $U_{N F}=[1-p(\beta)][Y+E]$.

\section{Proof:}

(i) If in the second stage, citizens make the decision to fight, and in consequence, we are in a fighting equilibrium, then the allocation that maximizes (7) is to give the workers the minimum, i.e. $\mathrm{W}=0$.

The elite's and workers' payoffs are then respectively:

\footnotetext{
${ }^{13}$ Quite naturally, $W$ is different in the cases of no-fight and fight, but we use the same notation $W$, for the sake of simplifying notations.
} 
$U_{F}=[1-p(\beta)] Y$

$V_{F}=p(\beta) Y-[1-p(\beta)] E$

(ii) For a non-fighting outcome to be an equilibrium it is necessary that:

$$
V_{N F} \geq V_{F}
$$

The elite's best response is to choose the smallest $\mathrm{W}$ that satisfies this inequality given (8b); that is:

$$
W=p(\beta) Y-[1-p(\beta)] E
$$

Substituting $\mathrm{W}$ in equation (5) leads to the elite's payoff:

$$
U_{N F}=[1-p(\beta)][Y+E]
$$

QED.

From lemma 1, one may now compute the optimal elite's payoffs under the various possible strategies as function of $\beta$ and $E$, and they are:14

$$
\begin{aligned}
& U_{R}=U_{R}^{*} \\
& U_{F}=[1-p(\beta)] Y \\
& U_{N F}=[1-p(\beta)][Y+E]
\end{aligned}
$$

Comparing equations (12) and (13), it is clear that the elite will prefer a no-fight solution to one in which citizens fight, therefore the characterization of the equilibrium solution involves then only the comparison between the payoffs $U_{R}$ and $U_{N F} \cdot{ }^{15}$

\footnotetext{
${ }^{14}$ It is interesting to note that when there are no upheavals, the elite can take resources higher than in a situation in which citizens never seek for democracy. This is due to the fact that when citizens are fighting and losing, their utility is negative, when one takes into consideration the punishments.

${ }^{15}$ We are aware that in reality, we sometimes face the situation of fights. This situation can occur if we assume that the timing of decisions is somehow different than the one presented in this model.
} 
This lemma states that only two possible situations can occur. If the elites choose to resign, they do not have any say on political and economic issues but they succeed to ensure themselves a minimal amount of resources "diverted" from the people. In this case, the elite of the past becomes the oligarchy of today. They have embezzled the assets through privatization, but at the same time have also permitted democratization, and therefore the demos do not fight.

The other possibility is that the elite decides to stay in power. This will occur when the elite gives enough resources to citizens to ensure that they prefer not to fight.

It remains to determine the optimal choice of the size of the repressive forces, $\beta^{*}$ by the elite. This optimal size is affected by the costs of repression. For sake of

simplicity, we assume that the costs of the repressive forces take the following form: ${ }^{16}$

$$
C(\beta)=c \beta^{2} / 2
$$

Then, we get that the net payoff structure for the elite in the first stage can be written as:

$$
\begin{aligned}
& \Omega_{R}(\beta)=U_{R}^{*}-c \beta^{2} / 2 \\
& \Omega_{N F}(\beta, E)=U_{N F}(\beta, E)-c \beta^{2} / 2
\end{aligned}
$$

where $\Omega_{R}$ is the net payoff in case the elites resign, and $\Omega_{N F}$ is the net payoff in case of no upheavals. We get the following lemma on the choice of the optimal amount of repressive forces, $\beta^{*}$.

\section{Lemma 2:}

(i) When rulers decide to resign, they choose a zero level of repression, and $\Omega_{R}=U_{R}^{*}$.

(ii) When rulers stay in power, they choose a level of repressive forces of $\beta^{*}$, solution of equation (16):

\footnotetext{
${ }^{16}$ We assume that the parameter $\mathrm{c}$ is constant. However, below in section IV, we also consider the case where $\mathrm{c}$ is not anymore constant, but a positive function of distance. The rationale for this assumption is that being far from the western world leads to technological backwardness, and therefore to a loss of the efficiency of the army.
} 


$$
d \Omega_{N F} / d \beta=0
$$

\section{Proof}

(i) When the elite resigns, her utility is given by equation (14), and therefore she chooses the optimal $\beta$ which is zero, and $\Omega_{R}=U_{R}^{*}$.

(ii) For the case of no-resign, when we substitute from equation (3) the punitive level into equation (15), we get:

$$
\Omega_{N F}(\beta)=[1-p(\beta)]\left[Y+A-\frac{(A-\lambda \beta)^{2}}{4 \beta \bar{t} \varphi(x)}\right]-\frac{c \beta^{2}}{2}
$$

The optimal $\beta, \beta^{*}$ which brings $\Omega_{N F}$ to a maximum is: ${ }^{17}$

$$
\beta^{*}=\frac{\lambda \delta A+2 \bar{t} \varphi(x) \delta[Y+A]}{\delta \lambda^{2}+2 c \bar{t} \varphi(x)}
$$

The net payoffs are presented in Figure 1, as well as the optimal amount of repressive forces, $\beta^{*}$.

We can now turn to the equilibrium chosen by the elite and the citizens. This is presented in Proposition 1.

\section{Proposition 1}

(i) When escaping costs are small such that: $\Omega_{N F}\left(\beta^{*}\right)<U_{R}^{*}$, then the elite does not invest in repressive forces, and will let the political system move from autocracy to democracy.

(ii) When escaping costs are high enough such that $\Omega_{N F}\left(\beta^{*}\right) \geq U_{R}^{*}$, then the elite chooses to stay in power, and invests in repressive forces of the size of $\beta^{*}$, given by equation (18).

\section{Proof}

The function $\Omega_{N F}$ is shown in Figure 1. We present a case in which escaping costs are high enough, so that $\Omega_{N F}$ at its maximum is higher than $U_{R}^{*}$. The maximum payoff is at the repressive forces of size $\beta^{*}$. If escaping costs are reduced, then from equation (17), we get that the whole curve $\Omega_{N F}$ moves

${ }_{17}$ We assume that parameters are such that $\beta^{*}$ is an interior maximum, i.e., $\delta^{2}(Y+A)<c$. 
downward. In case the whole curve will be lower than $U_{R}^{*}$, then it is optimal to choose $U_{R}^{*}$ and resign.

This proposition states that the distance to the free world affects the type of equilibrium which is chosen, either "to democratize", or "stay in power". In the next section, we analyze more specifically the relationship between the distance to the free world and the democratization process.

\section{Changes in Political Regimes}

Let us now consider how changes in the political regime of an autocratic country depend on its distance $x$ from the "free world". We first analyze the relationship between the optimal level of repressive forces and the distance to the free world.

\section{$\underline{\text { A. Relationship between distance and repressive forces }}$}

The next proposition stresses that the optimal level of repressive forces is negatively related to the distance of this country to the free world:

\section{Proposition 2}

The optimal amount of repressive forces $\beta^{*}$ is a decreasing function of the distance of the country to the free world, $x$.

\section{Proof}

Taking the total derivative of equation (16), we get that $d \beta^{*} / d x$ is:

$$
\frac{d \beta^{*}}{d x}=\frac{[\lambda \beta-A] \delta \lambda \varphi^{\prime}(x)}{\varphi(x)\left[\delta \lambda^{2}+2 c \bar{t} \varphi(x)\right]}<0
$$

We obtain that the derivative is negative, since the numerator is negative (from condition I). The intuition underlying Proposition 2 is simple. Geographic distance and policing are substitutes from the point of view of the expected cost of sanction as perceived by dissidents in this country. The further away is the country from the "free world", the less likely are the dissidents to make the decisions to move whenever an uprising is repressed. So the less profitable, in terms of perceived sanctions, it is to try to police after the underground dissidents escaping to the free 
world. Hence, there should be more intensive policing in countries closer to the free world frontier than in countries which are further away from it.

The next proposition states that, when we take into account the optimality of the repressive forces, the punitive level, $E$, is a non-monotonous function of the geographic distance to the free world.

\section{Proposition 3}

The expected punitive level, Ehas a U-shaped form in terms of the geographic distance to the free world, $x$.

\section{Proof}

Since in equation (3), the punitive level $E$, is a function of $x$ and $\beta$, by taking the total derivative of $\mathrm{E}$ as a function of distance, $x$ we get:

$$
d E / d x=\frac{\partial E}{\partial x}+\frac{\partial E}{\partial \beta} \frac{d \beta^{*}}{d x}
$$

Substituting the derivatives from equations (3) and (19), we get:

$$
d E / d x=\frac{\bar{t} \varphi^{\prime}(x)\left[4 c(Y+A)(\bar{t} \varphi(x))^{2}-\delta \lambda^{3} A\right]}{\sigma}
$$

where $\sigma$ is given by:

$$
\sigma=\frac{\delta \lambda^{3} A+2 \bar{t} \lambda \varphi(x)[\lambda \delta(Y+A)+c A]+4 c(Y+A)(\bar{t} \varphi(x))^{2}}{[A c-\lambda \delta(Y+A)]^{2}}>0
$$

Since the denominator of equation (21) is positive, we then get that:

$$
\begin{aligned}
& \text { if } \varphi(x)^{2} \leq \delta \lambda^{3} A /(2 \bar{t})^{2} c[Y+A] \text { then } d E / d x \leq 0 \\
& \text { if } \varphi(x)^{2}>\delta \lambda^{3} A /(2 \bar{t})^{2} c[Y+A] \text { then } d E / d x>0
\end{aligned}
$$


Since $\varphi$ is a positive function of $x$, then the derivative is first negative and then positive. Therefore the relationship between the punitive level, $E$ and the distance to the free world, $x$ takes a U-shaped form.

QED.

This proposition indicates that the relationship between distance to the "free world" and the punitive level is non-monotonous. A country that is closer to the "free world", does not always have a smaller punitive level than a country that is further away from the "safe haven", despite the positive direct effect of distance on the punitive level $\mathrm{E}$ (see equation 3).

It is interesting to note that the reason why $d E / d x \leq 0$ for small value of $x$ is related to the induced effect of geography on the repressive apparatus (i.e., proposition 2). This in turn means that the repressive response of incumbent elites to upheavals tends to be more intense when they are closer to the "free world" border than when they are further away.

The U-shaped relationship between geography and the size of the punitive level can pinpoint which country will be the first one to start an upheaval process. The trigger to this process of political change can be due, for instance, to a change in the average transportation costs per distance, $\bar{t}$, which we consider in the next section.

\section{$\underline{B}$. Transportation costs and changes in political regimes}

In the previous section, we have shown that there is a U-shaped relationship between the punitive level and the distance from the free world. This relation will permit us to analyze under which conditions, changes in political regimes are affected by geography.

\section{Lemma 3}

The net payoff, $\Omega_{N F}$ has a U-shaped form in terms of the geographic distance to the free world, $x$.

The net payoff to the rulers is given by equation (17). By adding the assumption that costs of repression are a positive function of distance, we get: ${ }^{18}$

\footnotetext{
${ }_{18}$ Moreover, we assume that $\mathrm{c}^{\prime \prime}(\mathrm{x})<0$, and that $\mathrm{c}^{\prime}(\mathrm{x})$ is large when $\mathrm{x}$ is near zero. As explained above, costs might be a positive function of distance, due to technological backwardness, and therefore to a loss of the efficiency of the army.
} 


$$
\begin{aligned}
& \text { if } \quad(A-\lambda \beta)^{2} \delta \varphi^{\prime}(x) / 2 \bar{t}[\beta \varphi(x)]^{2} \leq c^{\prime}(x) \text { then } d \Omega_{N F} / d x \leq 0 \\
& \text { if } \quad(A-\lambda \beta)^{2} \delta \varphi^{\prime}(x) / 2 \bar{t}[\beta \varphi(x)]^{2}>c^{\prime}(x) \text { then } d \Omega_{N F} / d x>0
\end{aligned}
$$

The net payoff as a function of distance is depicted in Figure 2.

In this section, we analyze the effects of a change in average transportation costs, $\bar{t}$ on the changes in political regimes. Let us assume that due to some exogenous changes in the foreign political factors as the international political arena, $\bar{t}$ is reduced. ${ }^{19}$ Let us analyze how this change from say $\bar{t}_{1}$ to $\bar{t}_{2}\left(\bar{t}_{2}<\bar{t}_{1}\right)$ may affect the political equilibrium across a set of authoritarian countries as ordered by their distance from the "free world".

Let us assume that when average transportation costs are $\bar{t}_{1}$, then for all countries, the equilibrium is that they do not choose to resign. Indeed even in country B, which is the country with the lowest net payoff in case of no-resign, there is no upheavals and the country was in an equilibrium of no-resign. In Figure 2 , we see that with transportation costs of $\bar{t}_{1}$, the payoffs to the elite of country B while no resigning, $\Omega_{N F}$ are higher than the payoff while resigning $U_{R}^{*}$, the threshold under which it is better to move towards democracy and resign (as explained in Proposition 1). Since country B, at distance $x_{B}$ from the free world is in equilibrium of no-resign, it is also so, for country A which is nearer the border to the "free world". ${ }^{20}$

When $\bar{t}_{1}$ is reduced to $\bar{t}_{2}$, as shown in figure 2 , the whole curve is moved downward. We now get that $\Omega_{N F}<U_{R}^{*}$ for country B. Then from proposition 1, it becomes optimal for the elite of country B to resign and to ensure the reservation utility level $U_{R}^{*}$ under a democratic process. Given the U shape of $\Omega_{N F}$, simple inspection of figure 2 , shows immediately that the first country to do undertake the democratization process is country B, and not country A with a distance $x_{A}$ to the free world, despite the fact that country A is closer to the "free world" frontier.

\section{Proposition 4}

When due to changes in the international political arena, $\bar{t}$ is reduced slightly, such that there is only one country that will undertake democratization, this country may not be the one nearest to the free world.

\footnotetext{
${ }^{19}$ Instead, we could assume that changes in the political arena leads to a decrease in $\lambda$, and we will obtain similar results.

${ }^{20}$ We assume that countries have the same characteristics, except for their distance from the free world.
} 
Proposition 4 states that the process of democratization will not start at the frontier of the free world. If there is only one country to start the process, it will not necessarily be the country nearest to the free world, which will start the process.

As mentioned in the introduction, proposition 4 can explain the transition process which took place in Eastern Europe in the late 1980s. Before the 80s, countries in Eastern Europe faced intense repression and a high punitive level. In terms of the comparison between equations (14) and (15), the optimal solution was to choose a high level of repressive apparatus, $\beta^{*}$, to stay in power without starting any democratization process. The repressive apparatus was high enough so that citizens did not fight. This was presumably the situation before the exogenous changes that took place in the end of the 1980s.

Due to Perestroika and the partial political reforms undertaken therein, the costs of transportation to escape dissident repression, $\bar{t}$ were reduced. East Germany was the country nearest the Western World, among the Communist countries. Yet, the process of transition did not start there. Consistent with our model, the country with a border with the free world is not the one with the smallest punitive level, since the army there was strong. We have shown that geography and repression are substitutes.

\section{Conclusion}

There is a large literature on the democratization process occurring in authoritarian political regimes, which mostly focuses on competition and redistribution between social groups. Far less emphasis, however, is placed on the geographical context of the political economy of dictatorial systems. This paper shows that geography can be a significant element of the democratization process.

This paper stresses that the decisions related to democratization are influenced by the geographic position of the country. The first main result of our paper is that the distance to the free world is an important factor influencing the decisions related to upheavals, and in consequence, the timing of democratization. The second result is that distance affects the democratization process through conflicting channels. In consequence, the country nearer the "free world" is not necessarily the first one to start a democratization process.

Our model is consistent with the democratization experience in Eastern Europe, as shown in figure 3, which highlights that the democratization process during the late 1980s was a U-shaped function of distance. 
This model may also be used to extrapolate on Asia. Indeed, our analysis also implies that the democratization in a given country may affect the choice of political regime in neighboring countries. This is so because the distance to the free world endogenously changes after the democratization of the first country. Hence a direct dynamic extension of our model would generate the possibility of spatial diffusion waves of democratization across neighboring countries.

In conclusion, our analysis provides some clues to where a democratization wave would begin. Our model suggests that political liberalization will not start directly from countries at the border of the free world, but rather may diffuse later to these countries after democratization started in some other part of the region, and the "free world "frontier moved as well.

Can our model be useful for understanding the democratization wave which is taking place in the Arab world? It seems clear that geography is relevant in these conflicts, since Tunisia, Libya, and Egypt are all neighboring countries. But, are we facing conflicting channels through which geography matters in this upheaval process? There are too many unknowns in this process to give a clear answer. In fact, there is even an unknown in whether this upheaval will indeed give place to democracy.

It could be that further research will show that the role of geography in the Arab world is driven by different forces than the ones our model has underlined, forces which have taken a central part in the transition process of Eastern Europe. It could be that technological progress and the appearance of new media such as facebook and twitter should be included in models of democratization, and lead to a different formulation of the framework. We leave that to further research.

\section{Bibliography}

Acemoglu, D. and J. Robinson. 2005. Economic Origins of Dictatorship and Democracy. Cambridge University Press.

Acemoglu, D. 2006. "A simple Model of Inefficient Institutions" Scandinavian Journal of Economics, 108: 515-546.

Acemoglu, D. and J. Robinson. 2008. "Persistence of Power, Elites, and Institutions" American Economic Review, 98(1): 267-93.

Alesina A. and E. Spolaore. 2003. The Size of Nations, MIT Press, Cambridge. 
Bairoch, P. 1997. Victoires et Deboires, vol. I. Paris: Gallimard.

Blanchard, O. Froot, K.A and JD Sachs. 1994. The Transition in Eastern Europe. Chicago: University of Chicago Press.

Blanchard, O. 1997. The Economics of Post-Communist Transition. Clarendon Press: Oxford.

Bolton, P. and G. Roland. 1992. Privatization Policies in Central and Eastern Europe. Economic Policy, 13: 275-309.

Boycko, M., Shleifer A., and R. Vishny. 1995. Privatizing Russia, MIT press, Cambridge.

Blockmans, W. 1978. "A Typology of Representative Institutions in Late Medieval Europe." Journal of Medieval History, 4:189-215.

Blockmans, W. 1997. "Representation (Since the Thirteenth Century)" In The New Cambridge Medieval History, ed. R. Mckitterick. Cambridge: Cambridge University Press.

Boulding, K. 1962. Conflict and Defense. New York: Harper \& Row.

Bourguignon, F. and T. Verdier. 2000. Oligarchy, democracy, inequality and growth. Journal of Development Economics 62, 285-313.

Bourguignon, F. and T. Verdier. 2010. "The Simple Analytics of Elite Behavior under Limited State Capacity", mimeo, PSE.

Brezis, E. S. and P. Temin. 2008. "Elites and Economic Outcomes" in New Palgrave, second edition ed. Durlauf. Amsterdam: Elsevier.

Brezis, E. and Schnytzer A. 2003. "Why are the Transition Paths in China and Eastern Europe Different? A Political Economy Perspective", Economics of Transition, 11:3-23.

Brezis, E. and T. Verdier. 2003. "Political Institutions and Economic Reforms in Central and Eastern Europe: A Snowball Effect" Economic Systems, 27:289-311.

Brezis, E. and P. Krugman. 1997. “Technology and Life Cycle of Cities", Journal of Economic Growth, 369-383.

Carneiro, R. L. 1970. "A theory of the origin of the state," Science 169: 733-38.

Carneiro, R.L. 1978. "Political expansion as an expression of the principle of competitive exclusion," pp. 205-223 in R. Cohen and E. R. Service (eds.) Origins of the State: The Anthropology of Political Evolution. Philadelphia: Institute for the Study of Human Issues.

Collier, P. and A. Hoeffler. 1998. "On the Economic Causes of Civil War", Oxford Economic Papers, 50: 563-573.

Diehl, P.F. 1991. “Geography and War: A Review and Assessment of the Empirical Literature", International Interactions 17(1): 11-27.

Fearon, J.D. and D.D. Laitin. 1999. "Weak States, Rough Terrain, and Large-Scale Ethnic Violence Since 1945", mimeo. 
Gates, S. 2002. "Recruitment and Allegiance: The Microfoundations of Rebellion", Journal of Conflict Resolution, 46:111-130.

Grossman, H.I. 1991. "A General Equilibrium Model of Insurrections" American Economic Review.

Herbst, J. 2000. States and Power in Africa. Princeton: Princeton University Press.

Jeffries, L. 1993. Socialist Economies and the Transition to the Market: a Guide. Routledge, NewYork.

Krugman, P.1991. Geography and Trade. MIT Press.

Leeson P. and A. Dean. 2009. "The Democratic Domino Theory: An Empirical Investigation" American Journal of Political Science, 53:3.

Lipton, D. and J.D. Sachs. 1990. "Privatization in Eastern Europe: the case of Poland" Brookings Papers on Economic Activity, 2: 293-341.

Mann, Michael. 1986. The Sources of Social Power: A History of Power from the Beginning to A.D 1760. Cambridge: Cambridge University Press.

Roland, G. 2000. Transition and Economics. MIT Press

Roland, G. and T. Verdier. 1999. "Transition and the Output Fall" Economics of Transition 7(1): $1-28$.

Spolaore E. , 2008. "Civil Conflict and Secessions", Economics of Governance, 45-63.

Sprout, H. and M. Sprout, 1965. The Ecological Perspective on Human Affairs. Princeton: Princeton University Press.

Stasavage, D. 2009. "Geographic Scale and Constitutional Control in the Process of European State Formation", mimeo.

Usher, D. 1989. "The Dynastic Cycle and the Stationary State" American Economic Review 79: 1031-44. 
Figure 1: The Elite's payoffs

Elite's payoffs

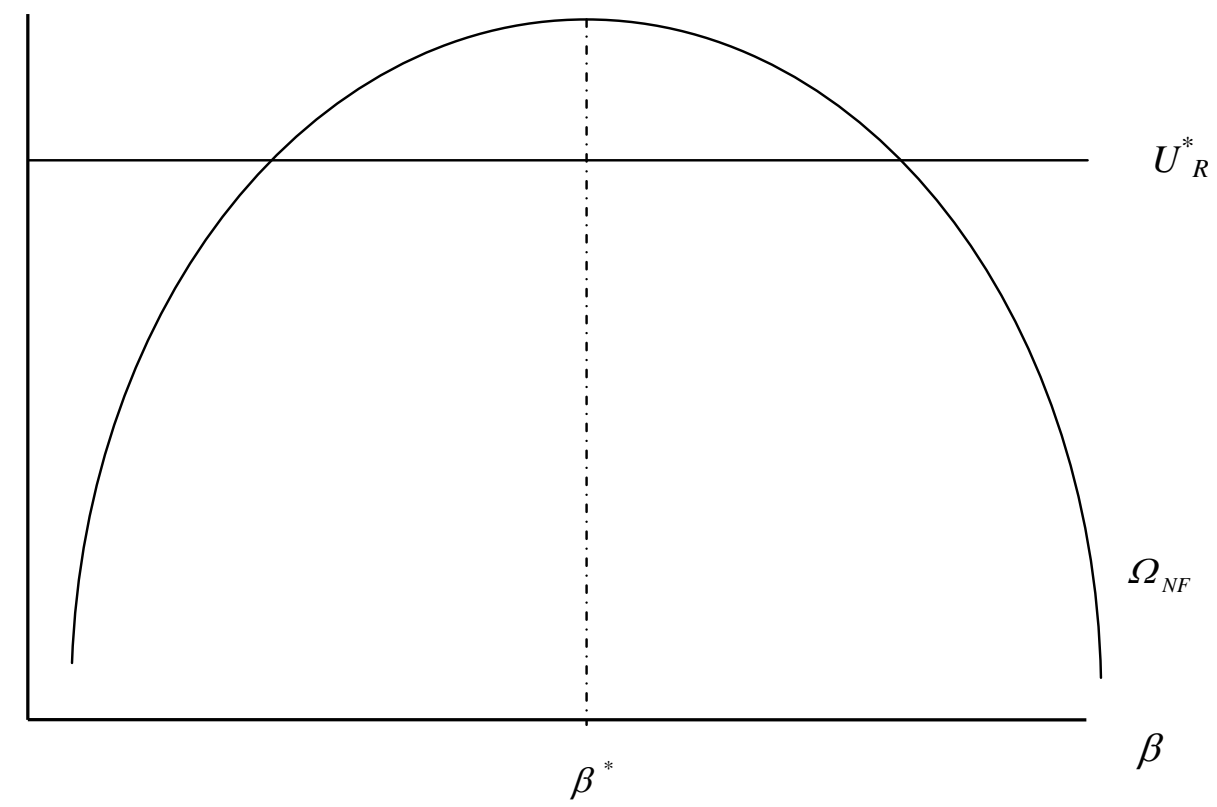


Figure 2: Net payoffs and political transition

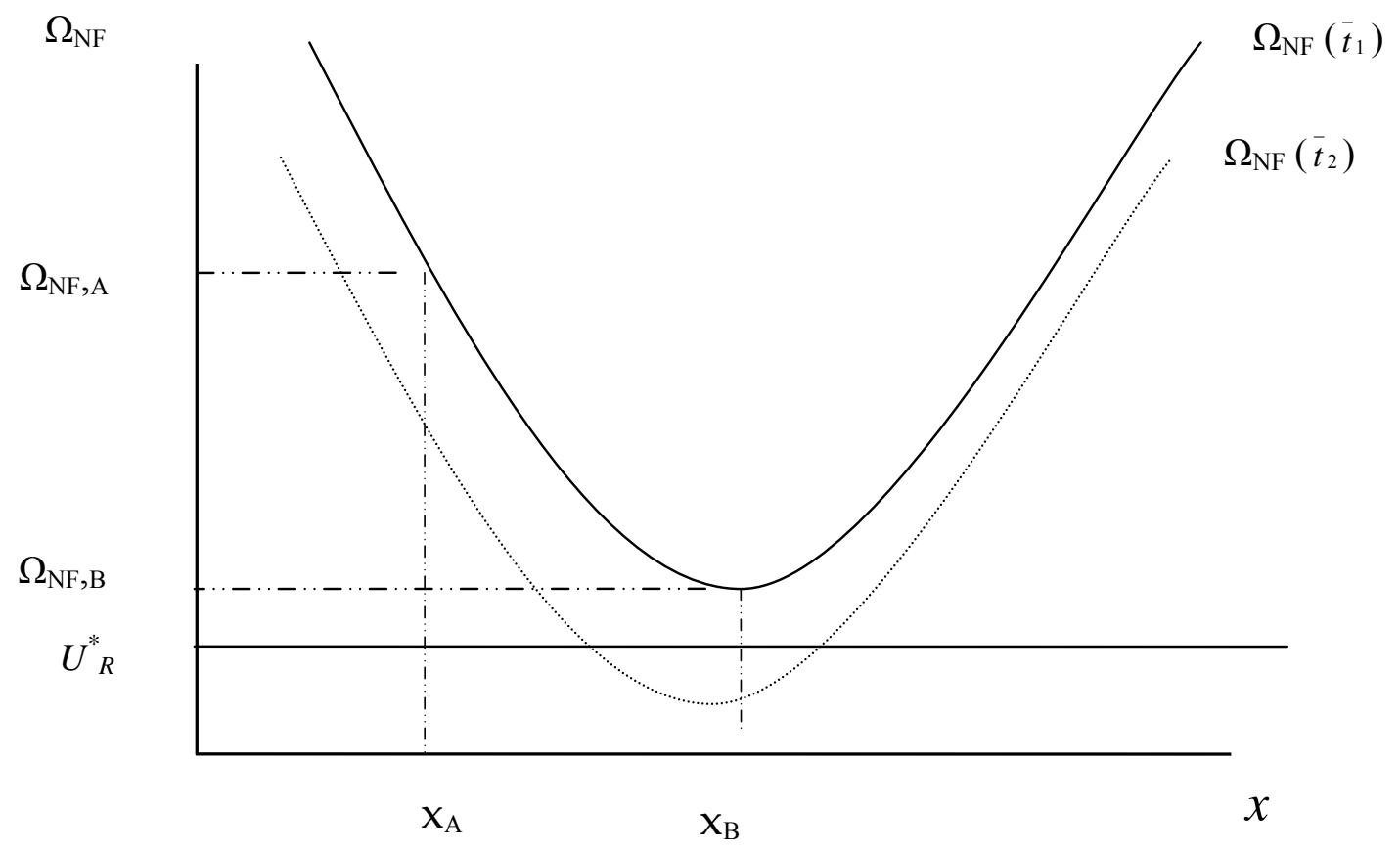


Figure 3: Transition Process in Eastern Europe

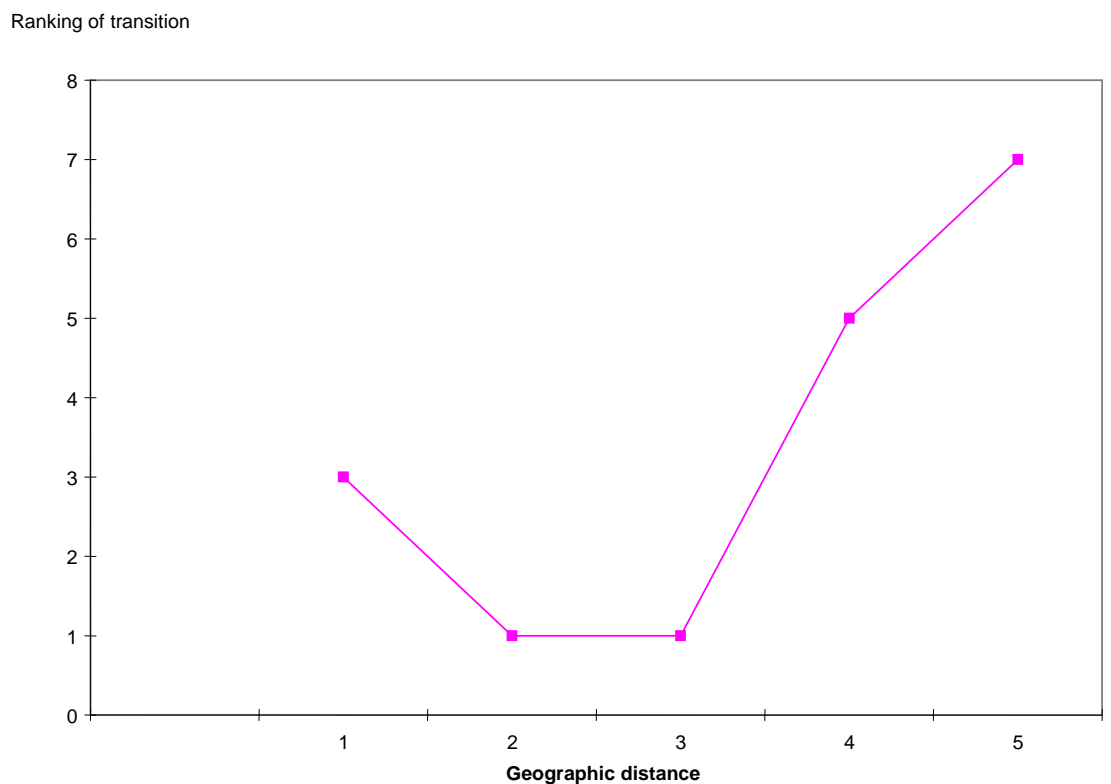

West. Eur. East-Germany Poland Hungary Czech. Yugoslavia

Source: The data on the timing of the transition come from Jeffries (1993). 